\title{
RESIDUAL STRESS PROFILE DETERMINATION BY THE HOLE-DRILLING METHOD WITH CALIBRATION COEFFICIENTS OBTAINED USING FEM
}

\author{
Fábio Junkes Corrêa, Frederico Alves Jahnert, Jucélio Pereira Tomás \\ Federal University of Paraná, Postgraduate Program in Mechanical Engineering, Curitiba - PR, Brazil \\ e-mail: fabiocorrea@utfpr.edu.br; fredjahnert@gmail.com; jucelio.tomas@ufpr.br
}

\begin{abstract}
Residual Stresses (RS) in mechanical components can be undesirable, and their accurate identification can prevent component damage. There are many semi-destructive methods for determination of RS. The hole-drilling method offers many advantages when compared to other methods due to its practicality, applicability to different materials, and low-cost execution. According to the American Society for Testing and Materials (ASTM) E837-13a Standard, the RS are assumed to be constant at each depth level when employing the hole-drilling method. Thus, calibration coefficients are necessary to calculate stress values at each level using the relaxed strains measured on the component surface, as incremental drillings are performed. However, the coefficients provided by the Standard were obtained using a coarsely-discretized 2D finite element model. This work aims to find new calibration coefficients based on the linear elasticity theory and using the Finite Element Method (FEM) with a refined mesh. A numerical model consisting of linear tetrahedral finite elements was constructed to simulate the resulting strains, as unitary stresses are applied at each depth level of the component inner surface. Using this method, two matrices of calibration coefficients are obtained, one related to normal stresses, and another related to shear stresses. The results show that the RS obtained using the new coefficients presented a $3.9 \%$ relative average error compared to analytical values in the four experiments conducted, while the ASTM Standard coefficients resulted in a $9.7 \%$ relative average error.
\end{abstract}

Keywords: semi-destructive methods, linear elasticity theory, finite element method, matrices of calibration coefficients

\section{Introduction}

In the development of mechanical projects, the study of Residual Stresses (RS) is essential. Depending on the magnitude, direction and location, they can considerably influence mechanical strength of the components. RS can be defined as the stresses that remain in the body, in equilibrium, without external loads. The application of mechanical, thermal or thermochemical processes can generate RS, such as mechanical forming processes, machining processes, casting processes, welding and heat treatments (Ghasemi and Mohammadi, 2016; Rickert, 2016; Rossini et al., 2012; Seifi and Salimi-Majd, 2012).

There are many methods for determining RS, including non-destructive, destructive, or semi-destructive methods. While non-destructive methods do not change the component functionality or mechanical strength, semi-destructive methods cause some damage to the component without compromising its operability. Considering each method applications and particularities, and the present stress distribution, the most appropriate one can be selected (Magnier et al., 2017, 2018). The hole-drilling method offers advantages such as practicality, applicability to different materials, and a relatively low execution cost. This technique consists of measuring relaxed strains on the component surface with the use of strain gauges, as a result of RS relief during incremental drillings. Considering that stresses vary with depth from the surface (Fig. 1), at 
each hole depth, there is a different stress value (Lothhammer et al., 2017; Puymbroeck et al., 2018).

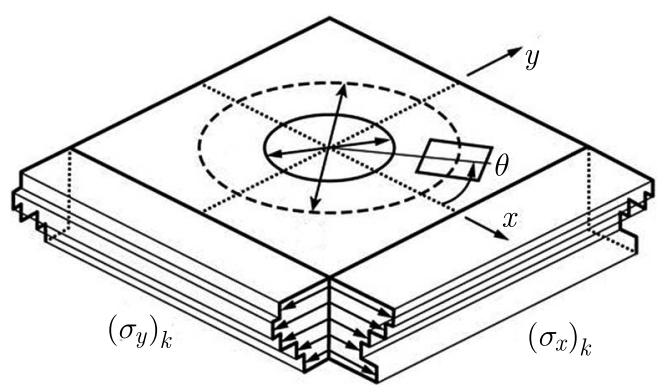

Fig. 1. Non-uniform residual stress profiles. Source: ASTM E837-13a (2013)

The RS assessment uses a mathematical relationship based on the linear elasticity theory, considering a state of plane stress for a linear, elastic and isotropic material (Allam et al., 2009, 2010; Lai et al., 2010; Sadd, 2014). For determination of the RS by employing the hole-drilling method, a rosette with three strain gauges is installed on the component surface, where relaxed strains are measured as an increasing hole depth is drilled in its center. According to the American Society for Testing and Materials (ASTM E837-13a 2013), considering a non-uniform RS profile, the stress for the $j$-th hole depth step is related to the measured relaxed strain on the surface $\varepsilon_{j}$ as

$$
\begin{aligned}
\varepsilon_{j}= & \frac{1+\nu}{E} \sum_{k=1}^{j} a_{j k} \frac{\left(\sigma_{x}\right)_{k}+\left(\sigma_{y}\right)_{k}}{2}+\frac{1}{E} \sum_{k=1}^{j} b_{j k} \frac{\left(\sigma_{x}\right)_{k}-\left(\sigma_{y}\right)_{k}}{2} \cos (2 \theta) \\
& +\frac{1}{E} \sum_{k=1}^{j} b_{j k}\left(\tau_{x y}\right)_{k} \sin (2 \theta)
\end{aligned}
$$

where $\left(\sigma_{x}\right)_{k}$ is the normal stress in the $x$-direction, $\left(\sigma_{y}\right)_{k}$ is the normal stress in the $y$-direction, $\left(\tau_{x y}\right)_{k}$ is the shear stress in the $x y$ plane, $E$ is Young's modulus, $\nu$ is Poisson's ratio, $a_{j k}$ and $b_{j k}$ are calibration coefficients obtained by the Finite Element Method (FEM), and $\theta$ is the orientation angle of each strain gauge. The calibration coefficients $a_{j k}$ and $b_{j k}$ adjust the rosettes geometry, hole diameter, distances between the extensometers and the hole, and more importantly, the hole depth (Schajer, 1988a,b). According to Eq. (1.1), the strain $\varepsilon_{j}$ measured by the extensometer is composed of a strain increments series $\varepsilon_{j k}$, where $j$ corresponds to the drilling stage, and $k$ the depth level. The summation of these strains $\varepsilon_{j k}$ results in the relaxed strain $\varepsilon_{j}$ following the superposition principle (Fig. 2). For example, the strain $\varepsilon_{j}$ for $j=3$ corresponds to the strain relaxation related to the third drilling stage of the hole.

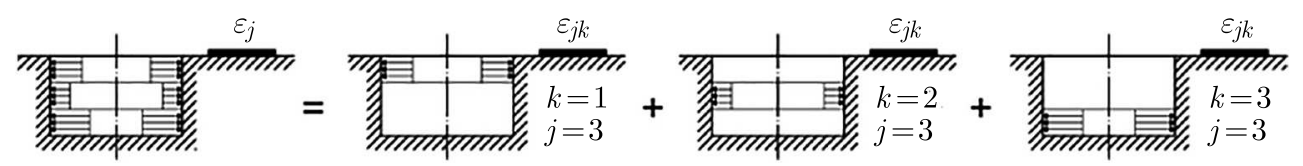

Fig. 2. Decomposition of the strain components measured in $j=3$. Source: Adapted of Peral et al. (2017a)

Initially, the RS can be calculated by finding the equiaxial strain $p_{j}$, the strain due to the difference between the longitudinal strain $q_{j}$ and the shear strain $t_{j}$ (Peral et al., 2017a,b; Schajer, 2007; Schajer and Prime, 2006). The strains measured for the hole depth step $j$ by the strain gauges in three directions correspond to the strain components $\left(\varepsilon_{a}\right)_{j},\left(\varepsilon_{b}\right)_{j}$, and $\left(\varepsilon_{c}\right)_{j}$. These 
strains measured on the surface can be combined with the variables $p_{j}, q_{j}$, and $t_{j}$ (Peral et al., 2017a,b; Schajer, 2007; Schajer and Prime, 2006), as

$$
p_{j}=\frac{\left(\varepsilon_{c}\right)_{j}+\left(\varepsilon_{a}\right)_{j}}{2} \quad q_{j}=\frac{\left(\varepsilon_{c}\right)_{j}-\left(\varepsilon_{a}\right)_{j}}{2} \quad t_{j}=\frac{\left(\varepsilon_{c}\right)_{j}+\left(\varepsilon_{a}\right)_{j}-2\left(\varepsilon_{b}\right)_{j}}{2}
$$

where $\left(\varepsilon_{a}\right)_{j},\left(\varepsilon_{b}\right)_{j}$, and $\left(\varepsilon_{c}\right)_{j}$ refer to the $j$-th strains in the $0^{\circ},-45^{\circ}$ and $-90^{\circ}$ directions in relation to the positive $x$ semi-axis. With $p_{j}, q_{j}$, and $t_{j}$ obtained, the isotropic biaxial stress $P_{k}$, the stress due to the difference between the normal stresses $Q_{k}$ and the shear stress $T_{k}$ for each depth level $k$ are found by solving the following equations

$$
\sum_{k=1}^{j} a_{j k} P_{k}=\frac{E}{1+\nu} p_{j} \quad \sum_{k=1}^{j} b_{j k} Q_{k}=E q_{j} \quad \sum_{k=1}^{j} b_{j k} T_{k}=E t_{j}
$$

The stresses $\left(\sigma_{x}\right)_{k},\left(\sigma_{y}\right)_{k}$, and $\left(\tau_{x y}\right)_{k}$, that correspond to the normal stresses in the $x$ and $y$ axes and the shear stress in the plane defined by these axes, respectively, and at the $k$-th depth level, can be combined with the variables $P_{k}, Q_{k}$ and $T_{k}$ (Peral et al., 2017a,b; Schajer, 2007; Schajer and Prime, 2006), as

$$
\left(\sigma_{x}\right)_{k}=P_{k}-Q_{k} \quad\left(\sigma_{y}\right)_{k}=P_{k}+Q_{k} \quad\left(\tau_{x y}\right)_{k}=T_{k}
$$

The principal stresses and the principal directions are found by calculating the eigenvalues and the eigenvectors, given by

$$
\left(\sigma_{\min }\right)_{k},\left(\sigma_{\max }\right)_{k}=P_{k} \pm \sqrt{Q_{k}^{2}+T_{k}^{2}}
$$

and

$$
k=\frac{1}{2} \arctan \frac{-T_{k}}{-Q_{k}}
$$

where $\left(\sigma_{\min }\right)_{k}$ is the minimum principal stress, $\left(\sigma_{\max }\right)_{k}$ is the maximum principal stress and $\beta_{k}$ is the principal direction.

The hole-drilling method is based on the use of the influence coefficients obtained by applying the FEM to a linear and elastic solid mechanics problem. The accuracy of the RS profile obtained is strongly dependent on the precision of these coefficients. However, these coefficients, presented by the ASTM E837-13a Standard published in 2013, have not changed so far and do not offer reliable results. Thus, this work aims to find new calibration coefficients using the linear elasticity theory and the FEM with a refined mesh, and estimates the RS profile across the depth of the component, employing the hole-drilling method. Therefore, the main contribution is to update the coefficients present in the Standard, resulting in a substantial improvement in the RS calculation accuracy using the accessible hole-drilling method.

\section{Materials and methods}

The calibration coefficient values $a_{j k}$ and $b_{j k}$ are found using a tridimensional finite element model. In this model, three markings are placed on the surface of the component where the displacements are read in three directions simulating a strain gauge rosette (Fig. 3).

On the finite elements surface, a circle was drawn in the center of the markings. This circle defines the region where incremental holes are drilled (Fig. 4). As drillings are performed, unitary stresses are applied to each level in the hole inner surface, and the radial displacements on the component surface are measured. The finite element mesh properties are shown in Table 1. 


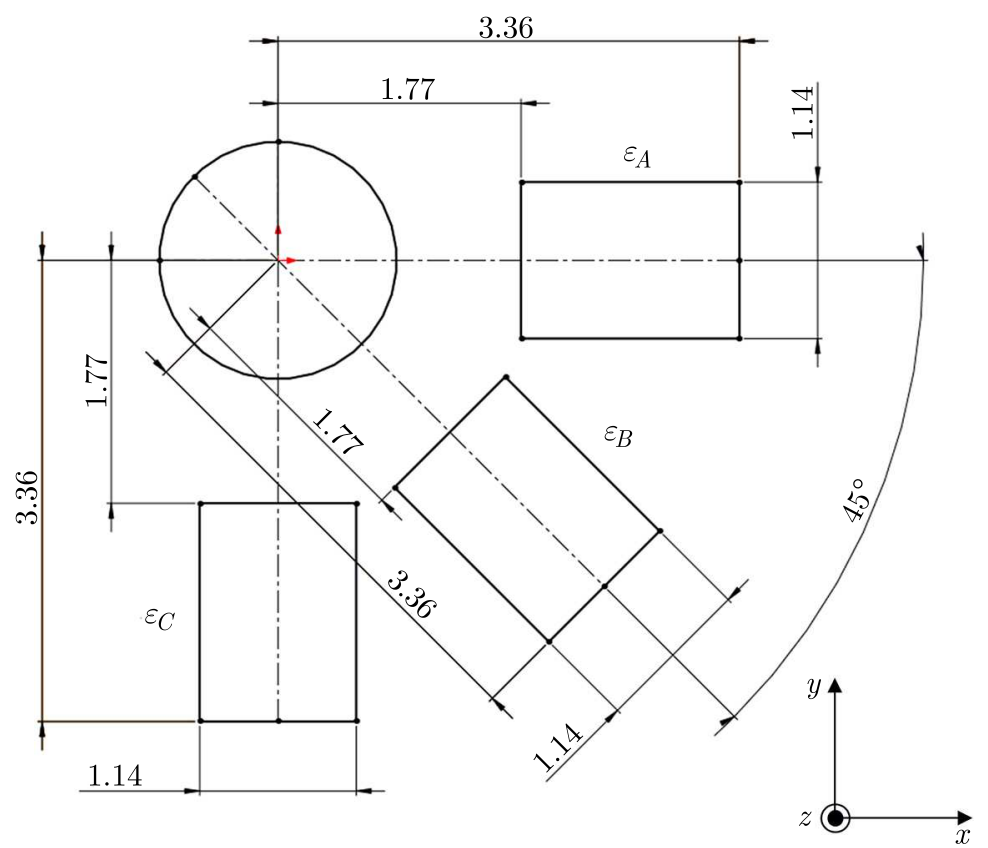

Fig. 3. Drawling of the rosette installation and drilled hole positions in the FEM model

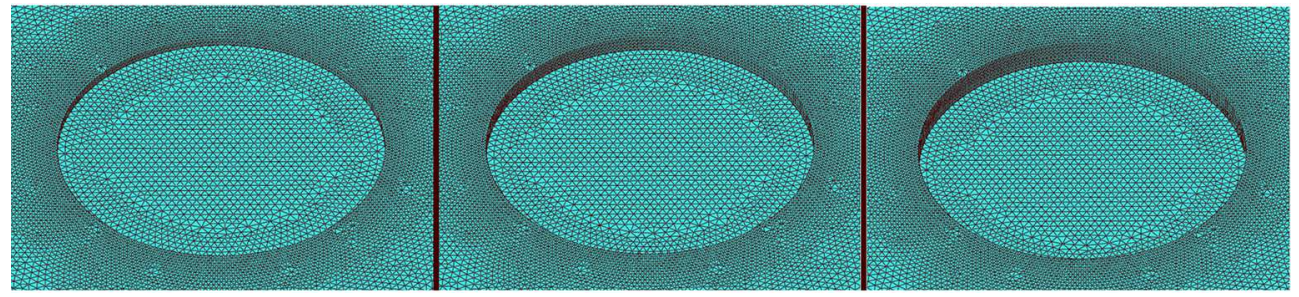

Fig. 4. Incremental drillings

Table 1. Model mesh properties

\begin{tabular}{|l|c|}
\hline \multicolumn{1}{|c|}{ Element type } & Linear tetrahedral \\
\hline \hline Maximum length of elements edges & $1.00 \mathrm{~mm}$ \\
\hline Minimum length of elements edges & $0.025 \mathrm{~mm}$ \\
\hline Total number of elements & 1056040 \\
\hline Total number of nodes & 195049 \\
\hline
\end{tabular}

The calculations of the $A_{j k}$ coefficients for the $j$-th drilling stage and the $k$-th depth level (Fig. 5) consider a central hole on the component, where axisymmetric loads are applied to the hole inner surface. The radial strains $\varepsilon_{j k}$ on the component surface are associated with the normal stresses present in the hole region $\left(\sigma_{x}\right)_{j k}$ and $\left(\sigma_{y}\right)_{j k}$ in the $x$ and $y$ directions, respectively, using the $A_{j k}$ coefficients (Niku-Lari et al., 1985), as

$$
\varepsilon_{j k}=A_{j k}\left(\left(\sigma_{x}\right)_{j k}+\left(\sigma_{y}\right)_{j k}\right)
$$

The biaxial stresses $\left(\sigma_{x}\right)_{j k}$ and $\left(\sigma_{y}\right)_{j k}$, called normal compression stresses, at each depth level, are shown in a longitudinal view in Fig. 5.

Considering an axisymmetric load on the hole inner surface as a biaxial load, the radial strains $\varepsilon_{j k}$ are calculated using the radial stress $\sigma_{j k}$ through the simplified equation (Niku-Lari et al., 1985)

$$
\varepsilon_{j k}=2 A_{j k} \sigma_{j k}
$$




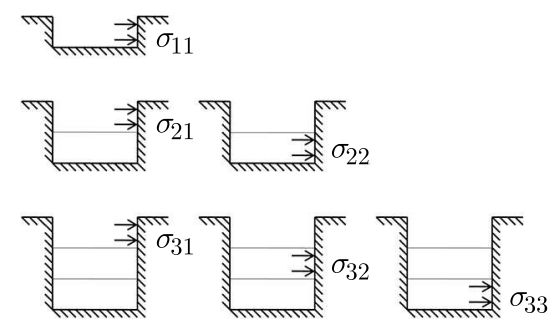

Fig. 5. Longitudinal view of the unitary stresses applied to the hole inner surface

and assuming a marking like a B type rosette, the strain can be calculated by

$$
\varepsilon_{j k}=\frac{U_{j k}^{r_{2}}-U_{j k}^{r_{1}}}{r_{2}-r_{1}}
$$

where $r_{1}$ is the distance from the hole center to the edge closest to the marking $(1.77 \mathrm{~mm})$, and $r_{2}$ is the distance from the hole center to the edge furthest of the marking $(3.36 \mathrm{~mm})$, $U_{j k}^{r_{1}}$ corresponds to the mean radial displacements of the closest edge and $U_{j k}^{r_{2}}$ corresponds to the mean radial displacements of the furthest edge (Niku-Lari et al., 1985).

The radial displacement on the surface can be found when the unitary stress $\sigma_{j k}$ is applied to on the hole inner side in each drilling level (Fig. 5). Since the calculated displacement can be related to the $A_{j k}$ coefficients, the two previous equations can be rearranged in the form

$$
\frac{U_{j k}^{r_{2}}-U_{j k}^{r_{1}}}{r_{2}-r_{1}}=2 A_{j k} \sigma_{j k}
$$

Considering a rosette with radius $r_{1}$ and $r_{2}$, the equation can be manipulated by isolating the variable $A_{j k}$, obtaining the equation

$$
A_{j k}=\frac{U_{j k}^{r_{2}}-U_{j k}^{r_{1}}}{2\left(r_{2}-r_{1}\right) \sigma_{j k}}
$$

As the unitary stresses applied are in each level, the radial displacements are determined at positions $r_{1}$ and $r_{2}$, and the coefficients are calculated. The normal compressive stresses applied are shown in Fig. 6 (Niku-Lari et al., 1985).

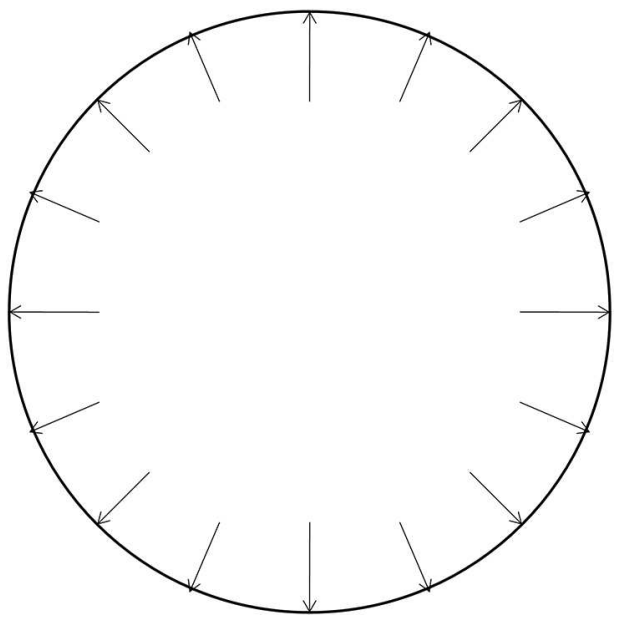

Fig. 6. Pressure stress on the hole inner surface in a cross-sectional view

With a simulation software (Abaqus) using the FEM, the unitary stresses are applied at each depth level, as shown in Fig. 5. The displacements in the surface markings are measured. 
The $B_{j k}$ coefficients can be calculated by applying a procedure similar to that used for the determination of the $A_{j k}$ coefficients. The $B_{j k}$ coefficients have a physical interpretation similar to the $A_{j k}$ coefficients. However, in this case, the loading is not axisymmetric. Instead of the unit $\sigma_{j k}=1$, a normal stress profile equal to $\cos (2 \theta)$ and a shear stress profile equal to $-\sin (2 \theta)$ are applied simultaneously in each depth stage. Thus, the applied stresses vary according to the circumferential position within the hole inner surface depending on the angle (Niku-Lari et al., 1985).

The normal stress applied to the hole inner surface is shown in Fig. 7. The maximum value occurs at $\theta=0^{\circ}, 180^{\circ}$ and $360^{\circ}$, the minimum value occurs at $\theta=90^{\circ}$, and $270^{\circ}$ and the null value at $\theta=45^{\circ}, 135^{\circ}, 225^{\circ}$ and $315^{\circ}$. Simultaneously, shear stresses are applied to the hole inner surface as shown in Fig. 8, where there is the maximum value at $\theta=135^{\circ}$, and $315^{\circ}$, the minimum value at $\theta=45^{\circ}$ and $225^{\circ}$, and the null value at $\theta=0^{\circ}, 90^{\circ}, 180^{\circ}, 270^{\circ}$ and $360^{\circ}$. The stress profile is applied to each depth level to obtain the coefficient for each drilling stage.

The values of the coefficients $B_{j k}$ can be obtained using the FEM displacement results on the component surface and applying the equation that considers the normal compressive stresses (Fig. 7) and the shear stresses (Fig. 8), given by Niku-Lari et al. (1985)

$$
\begin{aligned}
B_{j k} & =\frac{\left.\left(U_{j k}^{r_{2}}-U_{j k}^{r_{1}}\right)\right|_{\theta=0^{\circ}}+\left.\left(U_{j k}^{r_{2}}-U_{j k}^{r_{1}}\right)\right|_{\theta=90^{\circ}}}{4\left(r_{2}-r_{1}\right) \sigma_{j k}} \\
& +\frac{\left.\left(U_{j k}^{r_{2}}-U_{j k}^{r_{1}}\right)\right|_{\theta=0^{\circ}}+\left.\left(U_{j k}^{r_{2}}-U_{j k}^{r_{1}}\right)\right|_{\theta=90^{\circ}}}{4\left(r_{2}-r_{1}\right) \tau_{j k}}
\end{aligned}
$$

as shown in Fig. 5. With the displacements measured on the component surface, the coefficients $B_{j k}$ that make up the calibration matrix are found (Niku-Lari et al., 1985).

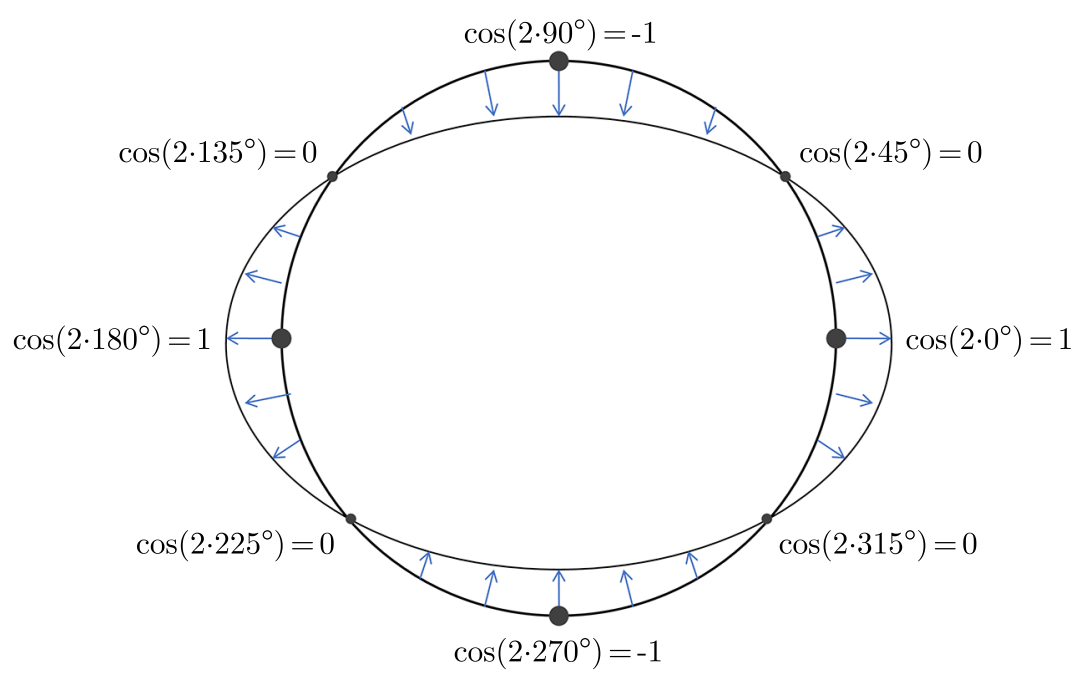

Fig. 7. Normal stress distribution on the hole inner surface in a cross-sectional view

The two calibration coefficients found $A_{j k}$ and $B_{j k}$ depend on the extensometers arrangement, material elastic properties, hole radius and depth. Thus, the measurements are required to be calculated for each material. Since these coefficients are material dependent, material non-dependent coefficients $a_{j k}$ and $b_{j k}$ were introduced. The dependence on elastic properties can be eliminated by defining two related dimensionless coefficients as (Schajer, 1988b)

$$
a_{j k}=\frac{2 E A_{j k}}{1+v} \quad b_{j k}=2 E B_{j k}
$$

The coefficients $a_{j k}$ and $b_{j k}$ are associated with biaxial stresses and with shear stresses, respectively. 


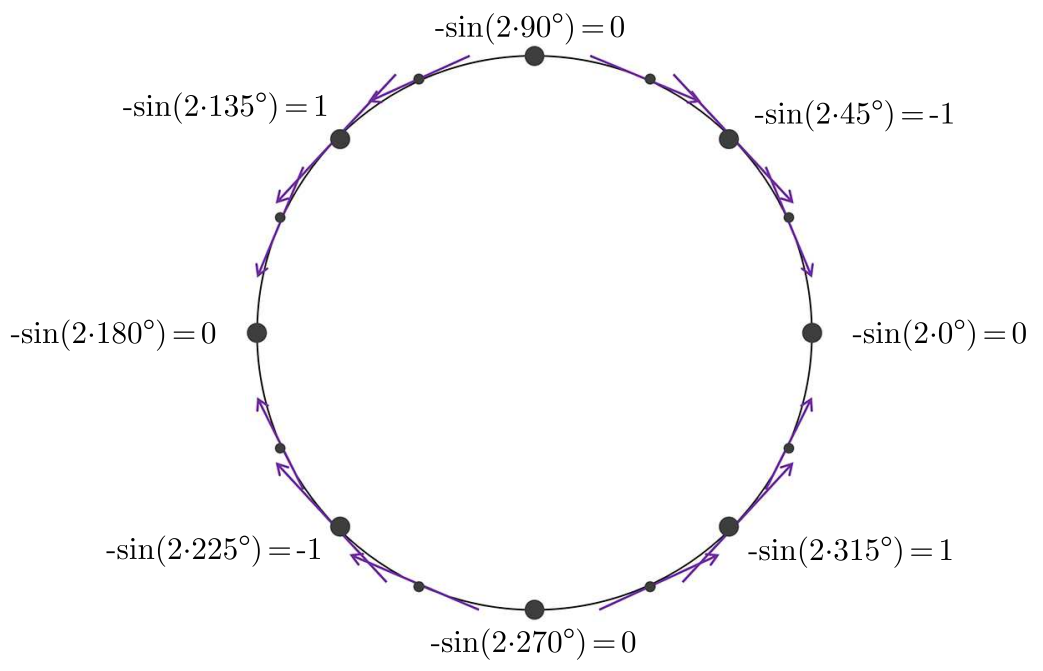

Fig. 8. Shear stress distribution on the hole inner surface in a cross-sectional view

\section{Results and discussions}

The results and discussions consist of two Sections. In the first Section, the calibration matrix coefficients are shown, and in the second Section, the determination of the RS profile using the calibration coefficients is analyzed.

\subsection{Coefficients of the calibration matrix}

The displacement values measured in the FEM model with the unitary stresses applied to the hole inner surface were used to calculate the constants $A_{j k}$ and $B_{j k}$ through equations (2.5) and (2.6). The material dependent constants are converted to dimensionless coefficients $a_{j k}$ and $b_{j k}$ by using the results obtained and equations (2.7). The new $a_{j k}$ coefficients (Table 2) are associated with the calculated normal stresses, and the new $b_{j k}$ coefficients (Table 3 ) are associated with the calculated shear stresses. These coefficients differ from those presented in the ASTM E837-13a Standard by approximately $4.3 \%$ for $a_{j k}$ coefficients and $7.0 \%$ for $b_{j k}$ coefficients, on average.

Table 2. Coefficients $a_{j k} \cdot 10^{-3}$

\begin{tabular}{|l|l|l|l|l|l|l|l|l|l|}
\hline-7.040 & & & & & & & & & \\
\hline-8.488 & -7.549 & & & & & & & & \\
\hline-9.662 & -8.935 & -7.734 & & & & & & & \\
\hline-10.683 & -9.986 & -9.102 & -7.707 & & & & & & \\
\hline-11.581 & -10.887 & -10.078 & -9.054 & -7.513 & & & & & \\
\hline-12.374 & -11.676 & -10.896 & -9.975 & -8.838 & -7.208 & & & & \\
\hline-13.067 & -12.363 & -11.595 & -10.720 & -9.703 & -8.491 & -6.805 & & & \\
\hline-13.672 & -12.963 & -12.199 & -11.348 & -10.388 & -9.303 & -8.041 & -6.345 & & \\
\hline-14.201 & -13.486 & -12.723 & -11.885 & -10.957 & -9.935 & -8.803 & -7.524 & -5.846 & \\
\hline-14.664 & -13.944 & -13.179 & -12.348 & -11.438 & -10.453 & -9.387 & -8.240 & -6.966 & -5.334 \\
\hline
\end{tabular}

The new coefficients found using the proposed methodology, as shown in Tables 2 and 3, were tested in the application of the hole-drilling method to calculate RS in physical experiments in the following Section. 
Table 3. Coefficients $b_{j k} \cdot 10^{-2}$

\begin{tabular}{|l|l|l|l|l|l|l|l|l|l|}
\hline-1.333 & & & & & & & & & \\
\hline-1.550 & -1.440 & & & & & & & & \\
\hline-1.728 & -1.659 & -1.499 & & & & & & & \\
\hline-1.887 & -1.828 & -1.724 & -1.524 & & & & & & \\
\hline-2.030 & -1.976 & -1.887 & -1.753 & -1.523 & & & & & \\
\hline-2.159 & -2.108 & -2.028 & -1.913 & -1.754 & -1.503 & & & & \\
\hline-2.273 & -2.226 & -2.150 & -2.045 & -1.908 & -1.731 & -1.465 & & & \\
\hline-2.376 & -2.331 & -2.258 & -2.160 & -2.034 & -1.880 & -1.690 & -1.415 & & \\
\hline-2.466 & -2.423 & -2.354 & -2.259 & -2.141 & -2.000 & -1.833 & -1.634 & -1.355 & \\
\hline-2.546 & -2.506 & -2.438 & -2.347 & -2.233 & -2.099 & -1.945 & -1.770 & -1.566 & -1.289 \\
\hline
\end{tabular}

\subsection{Determination of the RS profile using the calibration coefficients}

A mechanical experimental setup was constructed to physically simulate a fixed-free beam under bending (Fig. 9) with a known stress profile. This assembly consists of a support which holds the beam in the horizontal position and an eyebolt in which a force $P$ is applied through a weight suspended by a steel cable, causing bending stresses. The force $P$ is applied at a distance $L$ from the location where the rosettes are installed. As incremental drillings are performed with $0.05 \mathrm{~mm}$ depth steps, the relaxed strain values on the component surface are measured, according to the ASTM E837-13a Standard (Schajer, 2007; Schajer and Prime, 2006).

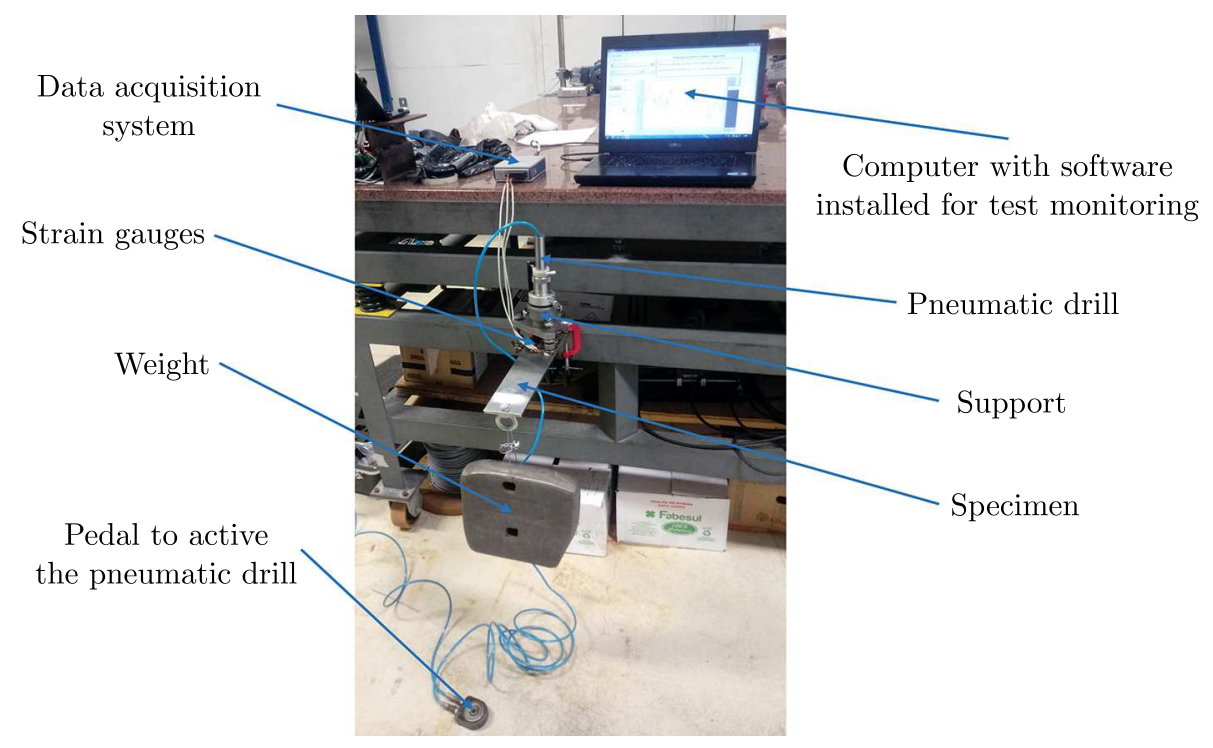

Fig. 9. Fixed-free beam experiment with the rosette installed on the component surface

The physical experiments were carried out using two AISI 1025 specimens with a $b \times h$ $(75.0 \mathrm{~mm} \times 5.3 \mathrm{~mm})$ rectangular profile. Two strain gauge rosettes of type B (Fig. 3) were installed at a distance $L=225.0 \mathrm{~mm}$ for the force $P=182.8 \mathrm{~N}$, inducing a linear stress distribution in the beam thickness, as shown in Fig. 10. The analytical stresses profile is obtained with the application of the following equation (Berrocal, 2007; Boresi and Schmidt, 2003)

$$
\sigma=\frac{ \pm 6 P L}{b h^{2}}
$$

The stress field generated varies from the maximum stress value (traction) of $117.2 \mathrm{MPa}$, on the upper surface $(z=2.65 \mathrm{~mm})$, to the minimum stress value (compression) of $-117.2 \mathrm{MPa}$, on 
the lower surface $(z=-2.65 \mathrm{~mm})$, as shown in Fig. 10. As the profile is analyzed to a depth of $0.5 \mathrm{~mm}$, the expected stress profile will range from $117.2 \mathrm{MPa}$ at the surface to a value of $94.2 \mathrm{MPa}$ at a depth of $0.5 \mathrm{~mm}$ from the surface. The applied force induces a linear normal stress profile in the longitudinal direction of the bar in its thickness, in which the maximum stress value is considerably below the material yield limit. The yield limit for AISI 1025 steel is about $350 \mathrm{MPa}$ (Berrocal, 2007; Boresi and Schmidt, 2003).
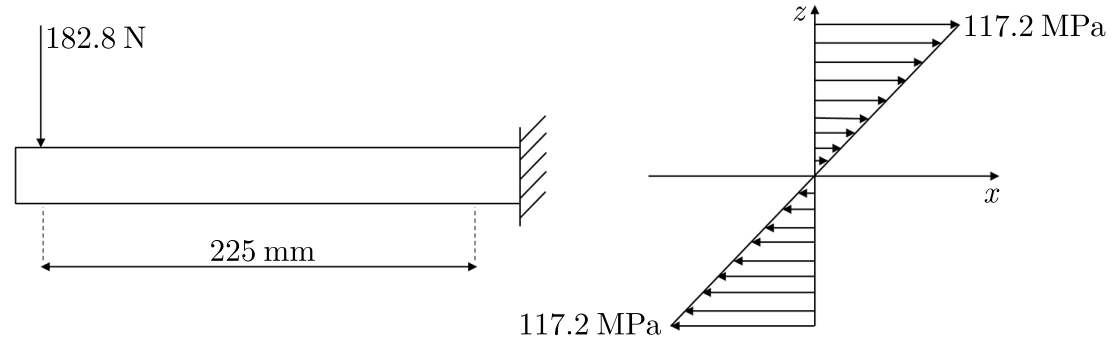

Fig. 10. Bending stress distribution due to application of the force

The hole-drilling method was applied using the calibration coefficients $a_{j k}$ and $b_{j k}$ present in the Standard and using the coefficients found in this work (Tables 2 and 3). Incremental drillings were performed with a step depth of $0.05 \mathrm{~mm}$ and, the relaxed strain values on the body surface were measured by the extensometers $\varepsilon_{A}, \varepsilon_{B}$ and $\varepsilon_{C}$ (Fig. 3). The relaxed strains were used to calculate the normal stresses and shear stresses at each depth level $k$, considering a state of plane stress, using equations $5,6,7,8,9$ and 10. Thus, the components of the stresses can be put in a matrix for each depth level $k$. The matrices eigenvalues and eigenvectors are calculated, identifying the maximum principal stresses and its directions (Lai et al., 2010; Sadd, 2014). With the principal stresses found for all depth levels, the maximum stress profiles are plotted as a function of the beam depth for the four experiments performed, as shown in Figs. 11, 12, 13 and 14, respectively. In these graphs, the black curves correspond to the analytical values, the green data refers to the stresses obtained using the calibration coefficients present in the ASTM Standard, and the blue data refers to the values found using the coefficients calculated in this work. As demonstrated in the graphs, according to the hole-drilling method (Alinaghian et al., 2019; Hosseini et al., 2019), the stresses are constant in each depth level, using the coefficients present in the Standard and those obtained in this paper.

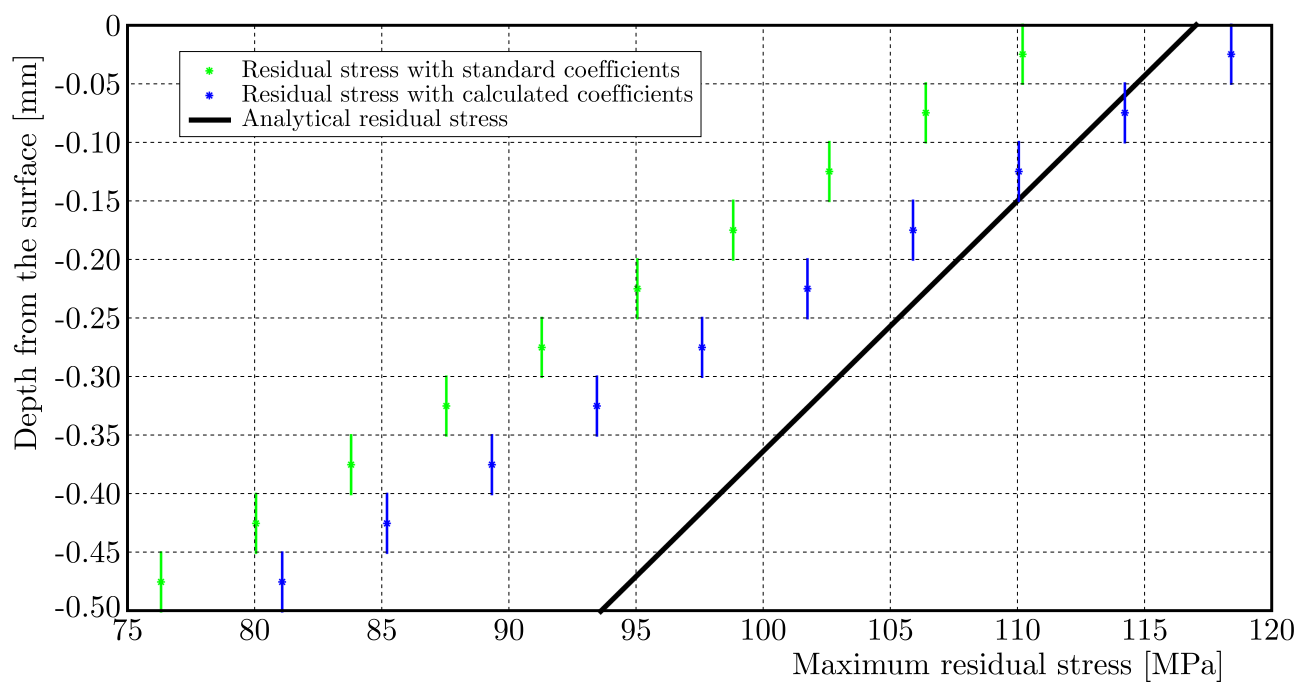

Fig. 11. Maximum residual stress profile as a function of the beam depth in the first experiment 


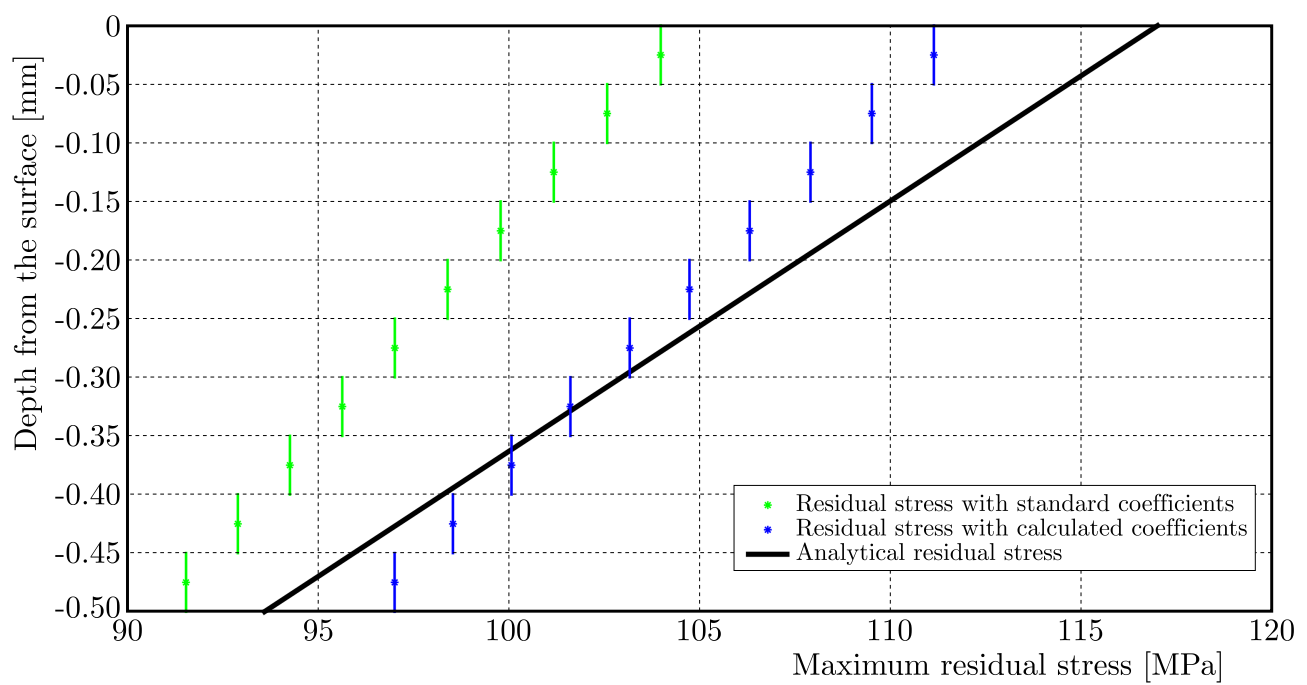

Fig. 12. Maximum residual stress profile as a function of the beam depth in the second experiment

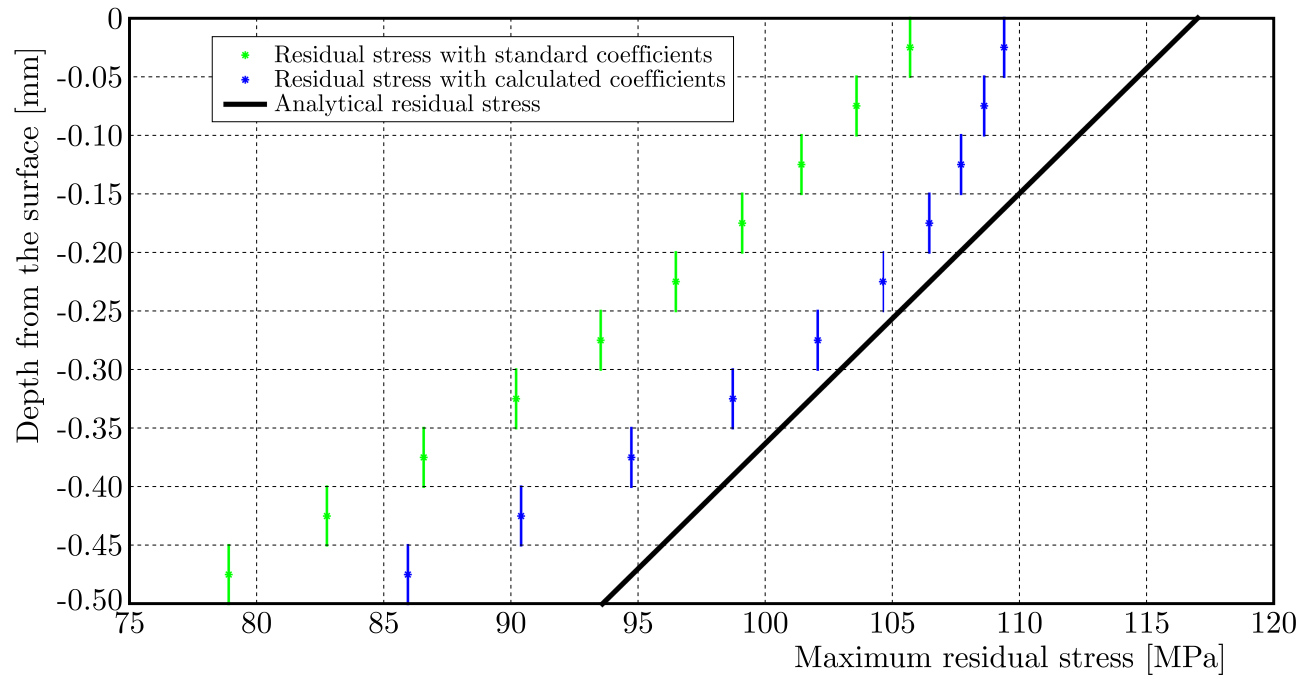

Fig. 13. Maximum residual stress profile as a function of the beam depth in the third experiment

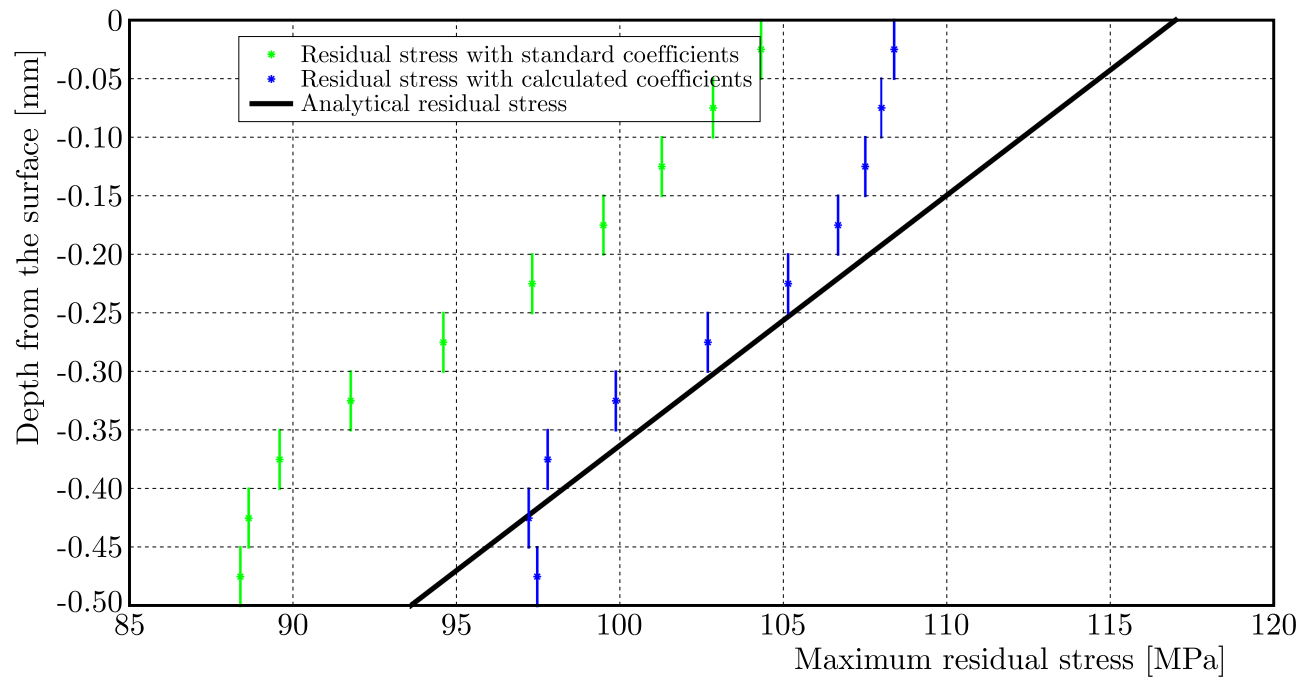

Fig. 14. Maximum residual stress profile as a function of the beam depth in the fourth experiment 
With the maximum stresses obtained at each depth level using the coefficients from the Standard and using the coefficients calculated, a comparative analysis can be made in relation to the analytical stresses. Table 4 shows the percentage error related to the analytical stresses for each depth level. It was noticed that for both methodologies, a greater error is present as the hole becomes deeper. This occurs due to the strain gauge sensibility and to the elliptical shape that the drilled hole assumes in deeper levels.

Table 4. Percentage errors relative to RS analytical values

\begin{tabular}{|c|c|c|c|c|c|c|c|c|c|c|c|}
\hline $\begin{array}{c}\text { Experim. } \\
\text { number }\end{array}$ & $\begin{array}{c}\text { Mean depth } \\
\text { hole }[\mathrm{mm}]\end{array}$ & 0.05 & 0.10 & 0.15 & 0.20 & 0.25 & 0.30 & 0.35 & 0.40 & 0.45 & 0.50 \\
\hline \hline \multirow{2}{*}{01} & $\begin{array}{c}\text { RS with } \\
\text { Standard } \\
\text { coefficients }\end{array}$ & $4.9 \%$ & $6.3 \%$ & $7.7 \%$ & $9.2 \%$ & $10.7 \%$ & $12.3 \%$ & $14.0 \%$ & $15.7 \%$ & $17.6 \%$ & $19.5 \%$ \\
\hline $\begin{array}{c}\text { RS with } \\
\text { calculated } \\
\text { coefficients }\end{array}$ & $2.2 \%$ & $0.6 \%$ & $1.0 \%$ & $2.7 \%$ & $4.5 \%$ & $6.3 \%$ & $8.2 \%$ & $10.2 \%$ & $12.3 \%$ & $14.4 \%$ \\
\hline $\begin{array}{c}\text { RS with } \\
\text { Standard } \\
\text { coefficients }\end{array}$ & $10.2 \%$ & $9.6 \%$ & $9.0 \%$ & $8.3 \%$ & $7.6 \%$ & $6.8 \%$ & $6.0 \%$ & $5.2 \%$ & $4.3 \%$ & $3.4 \%$ \\
\hline $\begin{array}{c}\text { RS with } \\
\text { calculated } \\
\text { coefficients }\end{array}$ & $4.0 \%$ & $3.5 \%$ & $2.9 \%$ & $2.3 \%$ & $1.6 \%$ & $0.9 \%$ & $0.2 \%$ & $0.6 \%$ & $1.5 \%$ & $2.4 \%$ \\
\hline \multirow{2}{*}{03} & $\begin{array}{c}\text { RS with } \\
\text { Standard } \\
\text { coefficients }\end{array}$ & $8.8 \%$ & $8.7 \%$ & $8.8 \%$ & $8.9 \%$ & $9.4 \%$ & $10.2 \%$ & $11.4 \%$ & $12.9 \%$ & $14.8 \%$ & $16.7 \%$ \\
\hline $\begin{array}{c}\text { RS with } \\
\text { calculated } \\
\text { coefficients }\end{array}$ & $5.8 \%$ & $4.6 \%$ & $3.4 \%$ & $2.4 \%$ & $1.9 \%$ & $2.3 \%$ & $3.5 \%$ & $5.6 \%$ & $8.4 \%$ & $11.6 \%$ \\
\hline $\begin{array}{c}\text { RS with } \\
\text { Standard } \\
\text { coefficients }\end{array}$ & $9.9 \%$ & $9.4 \%$ & $8.9 \%$ & $8.5 \%$ & $8.6 \%$ & $9.1 \%$ & $9.8 \%$ & $9.9 \%$ & $8.7 \%$ & $6.7 \%$ \\
\hline $\begin{array}{c}\text { RS with } \\
\text { calculated } \\
\text { coefficients }\end{array}$ & $6.4 \%$ & $4.8 \%$ & $3.3 \%$ & $2.0 \%$ & $1.2 \%$ & $1.4 \%$ & $1.9 \%$ & $1.7 \%$ & $0.1 \%$ & $2.9 \%$ \\
\hline
\end{tabular}

In addition to the relative percentage errors, the Root Mean Square Error (RMSE) can be calculated in order to examine the proximity between the values present in the RS profiles obtained and the values present in the analytical profiles with the application of the hole-drilling method, through the equation (Owen, 2010)

$$
\mathrm{RMSE}=\sqrt{\frac{1}{n} \sum_{i=1}^{n}\left(\widehat{P}_{i}-P_{i}\right)^{2}}
$$

where $\widehat{P}_{i}$ is $i$-th predicted value and $P_{i}$ is $i$-th experimental value. The RMSE is an error parameter which describes if the experimental values are closer or father from the analytical solution, with an increased weighting for the higher error, as shown in Table 5. It was found that the RS profiles obtained with the coefficients calculated in this work presented RMSE values almost halved when compared to those found with the coefficients in the Standard, showing a smaller variation in relation to the analytical profile. 
Table 5. RMSE relative to RS analytical values

\begin{tabular}{|c|c|c|c|c|c|c|c|c|c|c|}
\hline $\begin{array}{c}\text { Mean depth } \\
\text { hole [mm] }\end{array}$ & 0.05 & 0.10 & 0.15 & 0.20 & 0.25 & 0.30 & 0.35 & 0.40 & 0.45 & 0.50 \\
\hline \hline $\begin{array}{l}\text { RS with Standard } \\
\text { coefficients [MPa] }\end{array}$ & 11.42 & 11.25 & 11.19 & 11.31 & 11.65 & 12.26 & 13.04 & 13.80 & 14.40 & 15.01 \\
\hline $\begin{array}{l}\text { RS with calculated } \\
\text { coefficients [MPa] }\end{array}$ & 6.65 & 5.49 & 4.63 & 4.28 & 4.55 & 5.31 & 6.36 & 7.49 & 8.64 & 9.97 \\
\hline
\end{tabular}

\section{Conclusions}

The results show that with the new calibration coefficients proposed in this work based on the linear elasticity theory and using the FEM with a refined mesh, it was possible to obtain RS profiles in the beam depth closer to the analytically calculated RS profiles when compared to those obtained with the coefficients of the ASTM Standard. For each depth level, the RS profile results obtained using the new coefficients presented an average relative percentage error of $3.9 \%$ from the analytical values, while the ASTM Standard coefficients resulted in a $9.7 \%$ relative average error. Also, error improvements were found for every depth level using the new coefficients. Another indication of error distribution was calculated using the mean RMSE parameter. The calculated RS profile using the new coefficients exhibit a considerable increase in accuracy as the mean RSME value obtained is $6.4 \mathrm{MPa}$, while using the Standard coefficients, the mean RSME is $12.6 \mathrm{MPa}$. Thus, the new coefficients offer a substantial improvement in the accuracy of the RS analysis. These accuracy improvements in the coefficients lead to a better determination of the structural RS and, consequently, might improve structure failure prevention. The discrepancy between the obtained and analytical values might has occurred due to several factors, such as room temperature chances, drill radial displacement during drilling, tooltip wear, micrometric graduated drum handling errors for each drilling increment, material inhomogeneities, strain gauges sensitivity and vibrations during the drilling process.

\section{Acknowledgment}

This study was supported in part by the Coordination for the Improvement of Higher-Level Education - Brazil (CAPES) - Finance Code 001, Federal University of Paraná (UFPR), and Federal University of Technology - Paraná (UTFPR).

\section{References}

1. Alinaghian M., Alinaghian I., Honarpisheh M., 2019, Residual stress measurement of single point incremental formed $\mathrm{Al} / \mathrm{Cu}$ bimetal using incremental hole-drilling method, International Journal of Lightweight Materials and Manufacture, 2, 2, 131-139

2. Allam M.N., Elsibai K.A., Abouelregal A.E., 2009, Electromagneto-thermoelastic problem in a thick plate using Green and Naghdi theory, International Journal of Engineering Science, 47, $5-6,680-690$

3. Allam M.N., Elsibai K.A., Abouelregal A.E., 2010, Magneto-thermoelasticity for an infinite body with a spherical cavity and variable material properties without energy dissipation, International Journal of Solids and Structures, 47, 20, 2631-2638

4. ASTM E837-13a, 2013, Standard Test Method for Determining Residual Stresses by the Hole-Drilling Strain-Gauge Method, ASTM International, Conshohocken

5. Berrocal L.O., 2007, Resistencia de Materiales, 5th ed., McGraw-Hill, Madrid 
6. Boresi A.P., Schmidt R.J., 2003, Advanced Mechanics of Materials, 6th ed., John Wiley \& Sons, Hoboken

7. Ghasemi A.R., Mohammadi M.M., 2016, Residual stress measurement of fiber metal laminates using incremental hole-drilling technique in consideration of the integral method, International Journal of Mechanical Sciences, 114, 246-256

8. Hosseini S.M., Akbari S., Shokrieh M.M., 2019, Residual stress measurement through the thickness of ball grid array microelectronics packages using incremental hole drilling, Microelectronics Reliability, 102, 113473

9. Lai W.M., Rubin D., Krempl E., 2010, Introduction to Continuum Mechanics, 4th ed., Elsevier, Burlington

10. Lothhammer L.R., Viotti M.R., Albertazzi A., Veiga C.L.N., 2017, Residual stress measurements in steel pipes using DSPI and the hole-drilling technique, International Journal of Pressure Vessels and Piping, 152, 46-55

11. Magnier A., Scholtes B., Niendorf, T., 2017, Analysis of residual stress profiles in plastic materials using the hole drilling method - influence factors and practical aspects, Polymer Testing, $\mathbf{5 9}, 29-37$

12. Magnier A., Scholtes B., Niendorf T., 2018, On the reliability of residual stress measurements in polycarbonate samples by the hole drilling method, Polymer Testing, 71, 329-334

13. Niku-Lari A., Lu J., Flavenot J.F., 1985, Measurement of residual-stress distribution by the incremental hole-drilling method, Experimental Mechanics, 25, 2, 175-185

14. OWEN P.D., 2010, Limitations of the relative standard deviation of win percentages for measuring competitive balance in sports leagues, Economics Letters, 109, 1, 38-41

15. Peral D., Correa C., Diaz M., Porro J.A., De Vicente J., Ocaña J.L., 2017a, Measured strains correction for eccentric holes in the determination of non-uniform residual stresses by the hole drilling strain gauge method, Materials and Design, 132, 302-313

16. Peral D., de Vicente J., Porro J.A., Ochña J.L., 2017b, Uncertainty analysis for non-uniform residual stresses determined by the hole drilling strain gauge method, Measurement, 97, $51-63$

17. Puymbroeck E. van, Nagy W., Fang H., Backer H. De, 2018, Determination of residual weld stresses with the incremental hole-drilling method in tubular steel bridge joints, Procedia Engineering, 213, 651-661

18. Rickert T., 2016, Residual stress measurement by ESPI hole-drilling, Procedia CIRP, 45, 203-206

19. Rossini N.S., Dassisti M., Benyounis K.Y., Olabi A.G., 2012, Methods of measuring residual stresses in components, Materials and Design, 35, 572-588

20. SADD M.H., 2014, Elasticity: Theory, Applications, and Numerics, 3rd ed., Elsevier, Waltham

21. Schajer G.S., 1988a, Measurement of non-uniform residual stresses using the hole-drilling method. Part I - Stress calculation procedures, Journal of Engineering Materials and Technology, 110, October, 338-343

22. Schajer G.S., 1988b, Measurement of non-uniform residual stresses using the hole-drilling method. Part II - Practical application of the integral method, Journal of Engineering Materials and Technology, 110, October, 344-349

23. Schajer G.S., 2007, Hole-drilling residual stress profiling with automated smoothing, Journal of Engineering Materials and Technology, 129, 3, 440-445

24. Schajer G.S., Prime M.B., 2006, Use of inverse solutions for residual stress measurements, Journal of Engineering Materials and Technology, 128, 3, 375-382

25. Seifi R., SAlimi-Majd D., 2012, Effects of plasticity on residual stresses measurement by hole drilling method, Mechanics of Materials, 53, 72-79 